\title{
Stationary and Mobile Low-Cost Gas Sensor-Systems for Air Quality Monitoring Applications
}

\author{
Domenico Suriano, Mario Prato, Valerio Pfister, Gennaro Cassano, Giuseppe Camporeale, \\ Sebastiano Dipinto, Michele Penza \\ ${ }^{1}$ Lab Functional Materials and Technologies for Sustainable Applications, ENEA, Brindisi, Italy \\ michele.penza@enea.it
}

\begin{abstract}
This paper gives a short technical report on preliminary real-world measurements by low-cost gas sensor-systems for air quality monitoring. Measurements were performed by low-cost electrochemical gas sensors ( $\mathrm{CO}, \mathrm{NO}_{2}, \mathrm{O}_{3}, \mathrm{SO}_{2}$ ), optical particle counter/detector $\left(\mathrm{PM}_{1.0}, \mathrm{PM}_{2.5}, \mathrm{PM}_{10}\right)$, NDIR infrared sensor $\left(\mathrm{CO}_{2}\right.$ ), photo-ionisation detector (total VOCs), including miniaturized sensors for meteorological parameters (temperature, relative humidity). The sensors are running and installed in the city to assess the performance during a campaign of several months of operation in the framework of Italian national projects devoted to sustainable innovation in the smart cities. Relevant concentrations according to recommended values given by the European Directive (2008/50/EC) on Ambient Air Quality in Europe are in the low ppb-ppm range, depending on targeted pollutant. Our projects make use of two complementary approaches to achieve this challenge: stationary GSM-connected sensornodes distributed in the city and mobile sensor-systems GPS-connected to smartphone for indoorversus-outdoor applications. The first results indicate that these solutions are suitable for air quality monitoring with intensive inclusion to address indicative measurements (2008/50/EC).
\end{abstract}

Key words: Outdoor air quality, Gas/VOCs/PM detection, Stationary/Mobile sensor-systems, Realworld measurements

\section{Introduction}

Environmental monitoring is strongly required to protect the public health [1] and save the environment from toxic contaminants and pathogens that can be released into air. Airpollutants include carbon monoxide (CO), nitrogen dioxide $\left(\mathrm{NO}_{2}\right)$, sulfur dioxide $\left(\mathrm{SO}_{2}\right)$, particulate matter (PM), that originate from various sources such as vehicle emissions, power plants, refineries, industrial and laboratory processes. Ozone $\left(\mathrm{O}_{3}\right)$ detection is a key parameter to control the urban environment. Volatile organic compounds (VOCs) are critical for environmental protection and human health as well. Greenhouse gases $\left(\mathrm{CO}_{2}, \mathrm{CH}_{4}, \mathrm{~N}_{2} \mathrm{O}\right.$, etc. $)$ are important to be monitored in order to estimate the current trend of the sustainability in the smart cities and megacities. The World Health Organization (WHO) reports the air pollution as a significant risk factor for human health. This causes serious problems such as skin and eyes infections, irritations, heart diseases, bronchitis, asthma, lung cancer. Also, air pollution is one of the major causes for many premature deaths. Finally, air pollution not only has bad effects on public health but also on the environment such as acid rains, photochemical smog, ozone layer deterioration and global warming.

However, current monitoring methods are costly and time-consuming, also limitations in sampling and analytical techniques exist. Clearly, a need exists for accurate, inexpensive long-term monitoring of environmental contaminants using low-cost solid-state gas sensors that are able to operate on-site and real-time [2-8]. Calibrated cost-effective gas sensors are a very interesting solution for networked systems suitable to monitor air-pollutants in urban streets and real scenario of smart cities with high spatial and time resolution. Stationary and mobile approaches of sensor-systems for air quality monitoring are challenging for real-time and in-situ real-world measurements.

In ENEA, at Brindisi Research Center, a handheld gas sensor-system called AIRBOX based on solid state gas sensors was designed and implemented [9-19]. This system is the last result of our researches in the area of tiny and portable system for air quality control based on cost-effective solid state gas-sensors. The main goal of the system is the development of a portable equipment in order to detect some air- 
pollutant gases such as $\mathrm{CO}, \mathrm{SO}_{2}, \mathrm{NO}_{2}, \mathrm{O}_{3}$; volatile organic compounds (VOCs); particulate matter $\left(\mathrm{PM}_{1.0}, \mathrm{PM}_{2.5}, \mathrm{PM}_{10}\right)$; greenhouse gases $\left(\mathrm{CO}_{2}\right)$ and meteorological parameters (temperature, relative humidity) in the urban areas at outdoor level. This sensor-system is equipped by GSM-modem for wireless data communication towards a receiving server to create a database of environmental data collected by in-situ devices. A network of sensornodes has been deployed in the city of Bari (Italy) to assess the sensor performance in real scenario. Also, a portable gas sensor-system connected to smartphone has been investigated to monitor the cabin air quality in a car circulating in a city (Mesagne, Italy) during day-life traffic.

In this paper we report on preliminary measurements by stationary and mobile air quality sensor-systems for environmental monitoring applications in real scenario.

\section{Stationary AQ sensor-systems}

The sensor-system AIRBOX is equipped with 4 low-cost electrochemical gas sensors $\left(\mathrm{NO}_{2}, \mathrm{O}_{3}\right.$, $\left.\mathrm{CO}, \mathrm{SO}_{2}\right), 1$ NDIR sensor $\left(\mathrm{CO}_{2}\right)$ and 1 PhotoIonisation detector (tVOCs) by Alphasense Ltd (UK), 1 low-cost optical PM detector by Shinyei Technology Co Ltd (Japan), 1 temperature sensor (LM35CZ) by National Semiconductor Co. (USA), and 1 relative humidity sensor $(\mathrm{HIH}-$ 3610 Series) by Honeywell (USA).

The low-cost sensor-system is shown in the Fig. 1. The characteristics of the sensors for airquality monitoring are reported in the Table 1.

Tab. 1: Characteristics of AIRBOX sensors

\begin{tabular}{|c|c|c|c|}
\hline \multirow{2}{*}{ Gas } & \multicolumn{3}{|c|}{ Sensor Features } \\
\cline { 2 - 4 } & $\begin{array}{c}\text { Model / } \\
\text { Manufacturer }\end{array}$ & $\begin{array}{c}\text { Operating } \\
\text { range (ppm) }\end{array}$ & Size (mm) \\
\hline $\mathrm{NO}_{2}$ & $\begin{array}{c}\text { NO2A1 - B4 } \\
\text { Alphasense }\end{array}$ & $0-2$ & Diameter: 20 \\
\hline $\mathrm{O}_{3}$ & $\begin{array}{c}\text { O3A1 - B4 } \\
\text { Alphasense }\end{array}$ & $0-2$ & Diameter: 20 \\
\hline $\mathrm{CO}$ & $\begin{array}{c}\text { COCX - B4 } \\
\text { Alphasense }\end{array}$ & $0-20$ & Diameter: 20 \\
\hline $\mathrm{SO}_{2}$ & $\begin{array}{c}\text { SO2AF - B4 } \\
\text { Alphasense }\end{array}$ & $0-2$ & Diameter: 20 \\
\hline $\mathrm{CO}_{2}$ & $\begin{array}{c}\text { CO2 - NDIR } \\
\text { Alphasense }\end{array}$ & $0-3000$ & Diameter: 20 \\
\hline
\end{tabular}

\begin{tabular}{|c|c|c|c|}
\hline \multirow{2}{*}{ Gas } & \multicolumn{3}{|c|}{ Sensor Features } \\
\cline { 2 - 4 } & $\begin{array}{c}\text { Model / } \\
\text { Manufacturer }\end{array}$ & $\begin{array}{c}\text { Operating } \\
\text { range (ppm) }\end{array}$ & Size (mm) \\
\hline tVOCs & $\begin{array}{c}\text { VOCs-PID } \\
\text { Alphasense }\end{array}$ & $0-100$ & Diameter: 20 \\
\hline PM & $\begin{array}{c}\text { PPD20V } \\
\text { Shinvey }\end{array}$ & $\begin{array}{c}\text { Particle size: } \\
1-5 \mu \mathrm{m} ; \\
\text { Range: } \\
0-100 \mu \mathrm{g} / \mathrm{m}^{3}\end{array}$ & $59 \times 45 \times 22$ \\
\hline \multirow{2}{*}{ Temp } & $\begin{array}{c}\text { LM35CZ } \\
\text { National } \\
\text { Semiconductor }\end{array}$ & $-10^{\circ} \mathrm{C}-+80^{\circ} \mathrm{C}$ & $8 \times 5 \times 2$ \\
\hline $\mathrm{RH}$ & $\begin{array}{c}\mathrm{HIH}-3610 \\
\text { Honeywell }\end{array}$ & $0-90 \%$ & $6 \times 6 \times 2$ \\
\hline
\end{tabular}

In order to give AIRBOX a high flexibility grade, we have designed several modules: main board, sensor boards, USB port-hub, power module, GSM modem, GPS device. Main board is a Raspberry $\mathrm{Pl}$ module which is in charge to interface the end-user with the sensor boards, providing the necessary service implementing the equipment functionalities. Sensor boards communicate with main module via USB porthub following the master-slave scheme. The end-user interface is given by a web browser page by which operators can get machine full remote control. This is possible by connecting any $\mathrm{PC}$ with the web server running on the Raspberry board via Wi-Fi or LAN or GPRSUMTS connection.

AIRBOX can operate with several sensor boards at the same time by means of the USB hub and, therefore, it can run a great variety of sensors. The AIRBOX sensor-node is distributed in the city Bari (Italy) for air quality measurements as depicted in the Fig. 2.

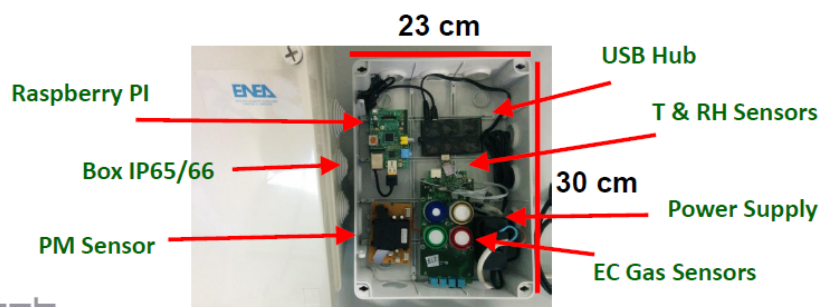

Fig. 1. AIRBOX sensor-system by ENEA (Brindisi) for air quality monitoring as node distributed in city.

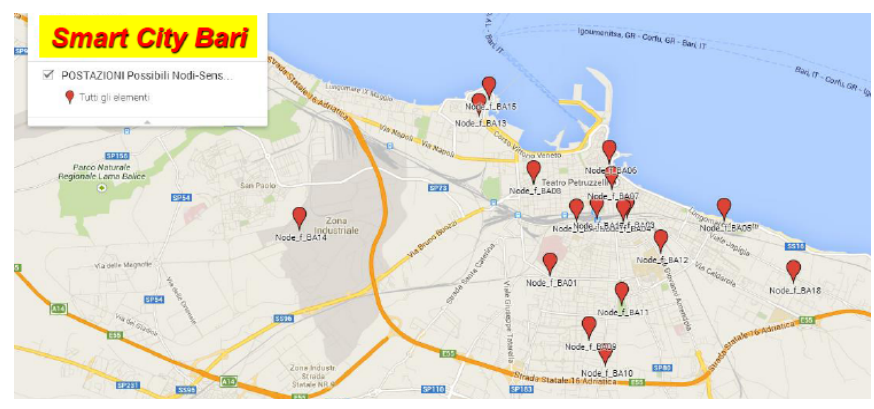

Fig. 2. Planned map of $A Q$ sensors network distributed at Bari (Italy) in the frame of RES-NOVAE project [9]. 
Currently, a long-term experimental campaign is running in the city to assess the sensor performance in real scenario. Preliminary results have shown that the selected low-cost sensors are very good candidates to monitor air pollution in continous regime. Fig. 3 shows the response of the electrochemical sensors $\left(\mathrm{O}_{3}\right.$, $\left.N_{2}\right)$ and the optical counter $\left(\mathrm{PM}_{10}\right)$ of the AIRBOX installed in city at location (Node 1). The $\mathrm{NO}_{2}$ and $\mathrm{O}_{3}$ detection is effective with both electrochemical sensors and their cross-relation is also existing [2]. Both sensors have measured concentrations in the range from 0 to $70 \mathrm{ppb}$. Further results concerning $\mathrm{PM}_{10}$ detection by optical counters are shown in the range from 10 to $50 \mu \mathrm{g} / \mathrm{m}^{3}$. Some instant peaks are regularly recorded as $150 \mu \mathrm{g} / \mathrm{m}^{3}$.
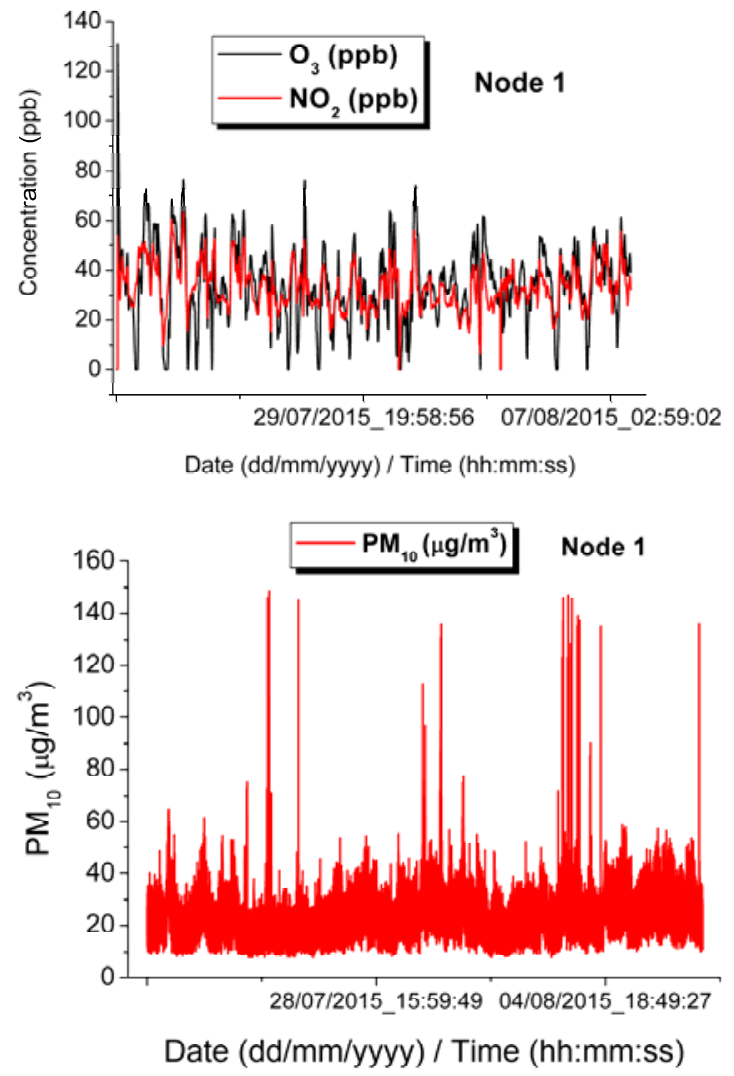

Fig. 3. Typical $\mathrm{NO}_{2}$ and $\mathrm{O}_{3}$ (top) and $\mathrm{PM}_{10}$ (bottom) time-tracks of AIRBOX sensor-system operated at city for long-period campaign (21 July 2015, time: 16:06 to 07 August 2015, time: 18:23 in city).

\section{Mobile AQ sensor-systems}

Participatory sensing is very important to involve citizens in the air quality monitoring. Thus, consumer technology as smartphone is very effective to enhance environmental awareness in the citizens. In order to detect low concentrations of air-pollutants, low-cost sensor modules connected to smartphone via Bluetooth are emerging in the air quality control. ENEA (Brindisi) has developed a prototype of portable sensor-system connected to smartphone via Bluetooth (see Fig. 4) in order to record air pollution during day-life.
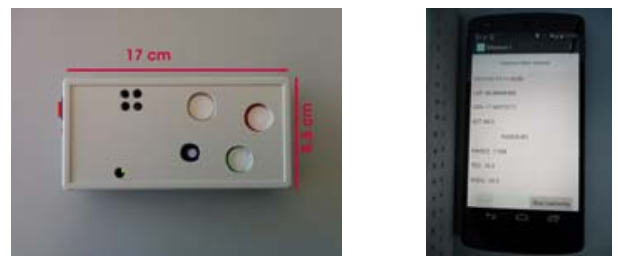

Fig. 4. Mobile gas sensor-system for cabin air quality monitoring and connected to a smartphone via Bluetooth.

We have evaluated this sensor-device during a test for cabin air quality monitoring. This sensor-system was installed in a car circulating in the city for a 2 hours (see Fig. 5). The results have shown that some peaks $\left(\mathrm{CO}, \mathrm{NO}_{2}\right)$ are recorded (see Fig. 6) during test, as expected.
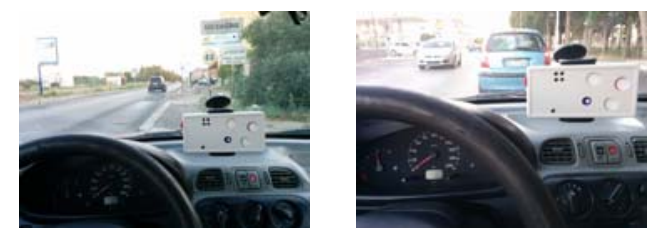

Fig. 5. Mobile gas sensor-system, mounted in car, for cabin air quality monitoring.
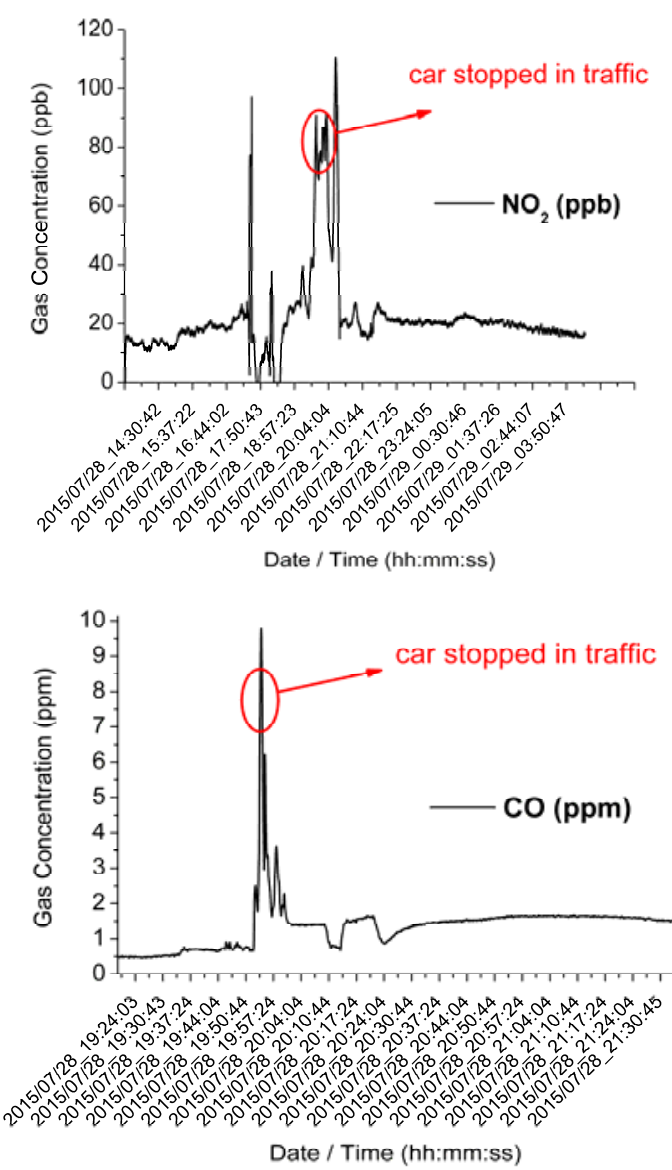

Fig. 6. Transient response of the mobile gas sensor-system for cabin air quality monitoring: a) $\mathrm{NO}_{2}$ sensor and b) CO sensor. 


\section{Conclusion and outlook}

The preliminary results achieved within the national projects for the city $\mathrm{AQ}$ monitoring by low-cost sensors are very promising. Of course, to achieve the overall goal of low-cost monitoring and accurate measurements, many problems remain to be solved, e.g. regular calibration, elimination of cross-interference, drift correction, enhanced selectivity to make full use of the potential provided by the low-cost sensor-systems for large involvement of the citizens in the air quality monitoring [20-22].

\section{Acknowledgements}

This work has been partially funded by national RES-NOVAE project (grant agreement No. PON4a2_E) and national BAITAH project (grant agreement No. PON1_00980) from Italian Ministry of University, Research and High Schools. The authors are strongly indebted to the COST Action TD1105 EuNetAir (20122016), which has provided valuable inputs through networking activities.

\section{References}

[1] F.J. Kelly, G.W. Fuller, H.A. Walton, and J.C. Fussell, Monitoring air pollution: use of early warning systems for public health, Respirology, 17, 7-19 (2012).

[2] M. Aleixandre and M. Gerboles, Review of small commercial sensors for indicative monitoring of ambient gas,Chemical Engineering Transactions, 30, 169-174 (2012)

[3] N. Kularatna and B.H. Sudantha, An environmental air pollution monitoring system based on the IEEE 1451 standard for low cost requirements, IEEE Sensors Journal, 8, 415-422 (2008).

[4] A.R. Al-Ali, I. Zualkernan, and F. Aloul, A mobile GPRS-sensors array for air pollution monitoring, IEEE Sensors Journal, 10 (10), 1666-1671 (2010).

[5] J.-H. Liu, Y.-F. Chen, T.-S. Lin, C.-P. Chen, P.-T. Chen, T.-H. Wen, C.-H. Sun, J.-Y. Juang, and J.A. Jiang, An air quality monitoring system for urban areas based on the technology of wireless sensor networks, International Journal on Smart Sensing and Intelligent Systems, 5(1), 191-214 (2012).

[6] D. Hasenfratz, O. Saukh, S. Sturzenegger, and L. Thiele, Participatory air pollution monitoring using smartphones, The $2^{\text {nd }}$ International Workshop on Mobile Sensing, April 16-20, 2012, Beijing, China. 2012 ACM 978-1-4503-1227-1/12/04.

[7] U.M. Lanjewar, J.J. Shah, Air pollution monitoring $\&$ tracking system using mobile sensors and analysis of data using data mining, International Journal of Advanced Computer Research, 2(4), Issue 6, 19-23 (2012).
[8] C.K. Ho, A. Robinson, D.R. Miller, and M.J. Davis Overview of sensors and needs for environmental monitoring, Sensors, 5, 4-37 (2005).

[9] http:// http://resnovae-unical.it/ricerca-1-bozza/

[10] European Sensor Systems Cluster (ESSC): www.cluster-essc.eu

[11] M. Penza et al., The European Sensor Systems Cluster - ESSC: A New EC Initiative, Linkoping EuNetAir Meeting, AMA Science 2015 Proceedings, Linkoping, Sweden, 3-5 June 2015.

[12] COST Action TD1105 EuNetAir webpages: www.cost.eunetair.it

[13] COST Action TD1105 EuNetAir ESSEM: http://www.cost.eu/domains actions/essem/Action s/TD1105

[14] M. Penza, COST Action TD1105: Overview of Sensor-Systems for Air Quality Monitoring, Procedia Engineering 87 (2014) 1370-1377.

[15] M. Penza et al., COST Action TD1105: New Sensing Technologies for Environmental Sustainability in Smart Cities, IEEE Sensors 2014 Proceedings, Valencia, Spain, 2-5 Nov. 2014. DOI: 978-1-4799-0162-3/14§31.00@2014 IEEE.

[16] M. Penza et al., COST Action TD1105: European Network on New Sensing Technologies for Air Pollution Control and Environmental Sustainability, ISOEN Symposium 2015 Proceedings, Dijon, France, 28 June - 1 July 2015

[17] M. Penza et al., COST Action TD1105: European Network on New Sensing Technologies for Air pollution Control and Environmental Sustainability, Linkoping EuNetAir Meeting, AMA Science 2015 Proceedings, Linkoping, Sweden, 3-5 June 2015.

[18] M. Penza, Portable Sensor-Systems for Air Quality Monitoring: The Case-Study of EuNetAir, 2nd Meeting of the Global Platform on Air Quality and Health, Geneva, Switzerland, 18-20 August 2015.

[19] M. Penza, COST Action TD1105: European Network on New Sensing Technologies for Air Pollution Control and Environmental Sustainability. Overview and Plans, Procedia Engineering 120 (2015) 476-479.

[20] US EPA Draft Roadmap on Next Generation of Air Monitoring (NGAM):

http://epa.gov/research/airscience/docs/roadmap20130308.pdf

[21] AQUILA Network on Air Quality National Reference Laboratories (http://ies.jrc.ec.europa.eu/aquila-homepage.html)

[22] EU Air Quality Directive 2008/50/EC (http://ec.europa.eu/environment/air/quality/legislati on/existing leg.htm) 